\section{VISTA Y PLANO DE TOLEDO}

\author{
Yasunari Kitaura
}

kitaura.y@gmail.com

Cómo citar este artículo/Citation: Kitaura, Y. (2015). "Vista y plano de Toledo". Arbor, 191 (776): a277. doi: http://dx.doi. org/10.3989/arbor.2015.776n6004

Recibido: 22 diciembre 2014. Aceptado: 9 marzo 2015.

RESUMEN: En Vista y plano de Toledo, que es fiel retrato y homenaje a la ciudad, tanto la visión de la Virgen como el desnudo de la izquierda, alegoría del río Tajo, sustento básico para la vida de la región representada por el joven de la derecha, son imágenes casuales aparecidas en el cielo, en la tierra y en los matorrales. La fantasía grequiana opera con un rigor casi matemático. Se observa una genealogía establecida entre la túnica de Jesús del Tríptico de Módena, la del ángel arrodillado del Bautismo del Prado y la casulla portada por la Virgen en Vista y plano. La composición de Vista y plano está relacionada con la Adoración de la primera época toledana, estableciendo un vínculo entre el joven con el plano y san Jerónimo con la Vulgata.

PALABRAS CLAVE: fantasía; espejismo; repoussoir; in maestà; sistema imaginativo; lógica imaginativa; equivalente; correspondencia; causalidad programática; procedimiento musical.

\section{VIEW AND PLAN OF TOLEDO}

Copyright: (c) 2015 CSIC. Este es un artículo de acceso abierto distribuido bajo los términos de la licencia Creative Commons Attribution-Non Commercial (by-nc) Spain 3.0.
ABSTRACT: In View and plan of Toledo, a faithful representation of the city and homage to it, the vision of the Virgin as well as the nude on the left, allegory of the river Tagus, sustenance of the life of the region represented by the youth clothed in olivegreen, all are casual images presented in the sky, on the earth and in the thicket. El Greco's imagination operates with almost mathematical rigour. A genealogical link can be traced between Jesus' tunic in the Modena-Triptych, the tunic of the kneeled angel of the Baptism of the Prado and the chasuble carried by the Virgin in Vista y plano. The composition of the picture is related to the Adoration of the first period, repeating the youth with the map the same role of Saint Jerome with the Vulgata.

KEYWORDS: fantasy; illusion; repoussoir; in maestà; imaginative system; imaginative logic; equivalent; correspondence; programmatic causality; musical procedure. 
Entre las obras de El Greco actualmente en el Museo del Greco de Toledo se encuentra un gran cuadro de paisaje que se titula Vista y Plano de Toledo (fig. a), obra maestra en la última época del pintor. La pintura perteneció en su origen a Pedro Salazar de Mendoza, último patrón importante del cretense.

La representación del paisaje toledano realizada por El Greco aparece por primera vez en el Martirio de San Mauricio y la Legión Tebana, después fue creciendo gradualmente como uno de los elementos importantes de su pintura y llega a su punto culminante en este cuadro que estudiamos aquí. Para observar con claridad este proceso basta seguir en orden cronológico las obras siguientes: San Mauricio (1580-82) -San José y el Niño Jesús y San Martín y el Mendigo (ambos 1597-99) -Laocoonte (hacia 1610) -Vista y Plano de Toledo (1610-14). Al observar esta sucesión de las obras, se impone el proceso por el que el paisaje toledano, que ocupaba solamente una pequeña parte del cuadro de forma muy discreta, va invadiendo el espacio pictórico y así engullendo a las figuras humanas hasta terminar disolviéndolas en su propio organismo. Tanto el fragmento insertado en San Mauricio como el paisaje representado en Vista y Plano se diferencian por su realismo delicado de otros paisajes más visionarios que pintó El Greco. Este proceso hubiera sido tan perfecto hasta poder convertirse en una regla, si hubiese sido pintado el otro cuadro Vista de Toledo (1600-1605) del Metropolitan Museum de Nueva York después de la última obra citada, donde todavía no han abandonado las figuras humanas su papel preponderante en la composición. En esta obra neoyorquina, aunque las figuras humanas no han desaparecido del todo, ellas completamente aplastadas ante la presencia cósmica de la Naturaleza, se han convertido en minúsculos puntos impotentes.

En Vista y Plano de Toledo las dos figuras humanas colocadas en ambos lados del lienzo no son figuras reales, ni constituyen ya los motivos principales de la composición. Tanto la figura desnuda a la izquierda, pintada como la alegoría del río Tajo, como la imagen del joven con aspecto de fantasma, completamente desmaterializado, que nos enseña un plano de la ciudad trazado con gran precisión, no son los protagonistas de la escena representada. Su protagonista es el mismo paisaje de Toledo, pintado con un realismo extraordinario, que se despliega en el fondo de estas figuras humanas del primer plano. $Y$ por ser protagonista ha dejado de ser el fondo de la pintura. En este sentido, esta vista toledana se distingue esencialmente del paisaje, a primera vista parecido, que aparece en el fondo del Laocoonte tomado, más o menos, desde el mismo ángulo. El paisaje toledano que aparece en este lienzo de Washington está pintado literalmente como el fondo para el grupo de las figuras humanas del primer término, protagonistas de la escena, a cuya preeminencia se subordina desde el punto de vista de la jerarquía pictórica. Lo que demuestra este hecho mejor que ninguna otra cosa es la parte de la ciudad que desaparece de repente en el lado izquierdo del joven desnudo que se estira con una serpiente en las manos que está a punto de morder su costado. La desaparición arbitraria de la ciudad no obedece sino al propósito de resaltar la bella silueta de la figura juvenil, y para cumplir este objetivo artístico, la parte de la ciudad que se sitúa detrás de este motivo importante fue sacrificada sin misericordia por el pintor. En contraste, la parte urbana escogida, al parecer con una clara intención, dentro de la forma del corazón creada por la curva de la serpiente y los brazos del muchacho, ¿tendría algún significado otorgado por el cretense? En todo caso aquí la realidad urbana está manipulada totalmente por el autor para ser adaptada libremente a su fantasía. En el caso de Vista y Plano de Toledo esta relación se invierte: las figuras humanas asisten a la ciudad. Se advierte igualmente que el grupo de la Virgen y los ángeles suspendido en el aire (fig. b) juega un papel similar a una hermosa corona o un manojo de flores para embellecer y consagrar la noble ciudad imperial. En Vista de Toledo del Metropolitan Museum no se ha producido todavía semejante inversión entre el sujeto y el complemento a pesar de que la diferencia proporcional entre el paisaje y las figuras se extrema.

Jamás se había pintado hasta entonces un paisaje con un realismo a la vez tan riguroso y delicado como Vista y Plano de Toledo. Las colinas toledanas se extienden sobre la meseta castellana trazando suaves ondulaciones en torno a la ciudad, y su línea del horizonte se difumina después de dibujar una leve curva como si quisiera indicar la forma esférica del planeta. $\mathrm{Y}$ justo en el punto culminante de este arco amplio, pero bastante desplazado hacia la izquierda del centro del espacio pictórico, se yergue la sombría silueta de la torre de la catedral, único monumento visto a contraluz. La tierra de color pardo, humedecida, acaba de terminar, por lo visto, su época de cosecha, y el agua crecida del río Tajo corre en torrente espumado. Sopladas por un viento, las nubes lluviosas se alejan velozmente de lo alto de la ciudad, y por la tenue luz del sol de la tarde que sale entre las nubes resplandecen en color gris plateado los tejados de las casas apiñadas de la ciudad. Los toques de las pinceladas 
son tan modernos que evocaron tanto a Camón Aznar como a Wethey los empleados por Cézanne. Ahora bien, en lo alto de esta ciudad justo encima de la torre de la catedral, El Greco pinta a la Virgen con una casulla rodeada de ángeles como una aparición milagrosa y repentina: el grupo visionario es tan bello como un arco iris y es también como él tan carente de cualquier sentido de substancia. Quizá se puede incluir entre los mejores trozos pintados por El Greco.

Todos los motivos formales y cromáticos, que constituyen el grupo entero formado en torno a la mancha de colores rosa y azul blanquecinos que configura a la Virgen, se congregan hacia dentro con una fuerza centrípeta, al mismo tiempo que se expanden hacia fuera con una fuerza centrífuga, creando así una masa cromática con una tonalidad delicada y con un vivo sentido de equilibrio dinámico. En esta obra El Greco respetó ante todo la realidad del paisaje. Es un realismo común que se encuentra en el Retrato de Jerónimo de Cevallos, por ejemplo, que pertenece también a la última época. Lo que sostiene substancialmente el sentido real y la plasticidad trémula de todos los objetos pintados de la obra es la imprimación del color pardo que se transparenta en todas las partes. $\mathrm{Ni}$ la viva presencia de la hilera de casas en vibrante gris plateado, ni la transparencia de la atmósfera húmeda y profunda, que circula con honda respiración, hubiera sido posible representarse sin este procedimiento técnico que aprovecha al máximo la imprimación y utiliza, al mismo tiempo, colores muy delgados con un dominio magistral. La visión es, por así decirlo, un arco iris colocado sobre este espectáculo real del paisaje. Se armoniza de una manera admirable con el cielo ventilado y palpitante. Si este grupo magistral hubiese sido plasmado con mayor definición en sus detalles y pigmentado con mayor pastosidad y densidad, se hubiera perdido completamente su equilibrio con el paisaje entorno. El grupo hubiera perdido igualmente su cualidad de ser una visión por haber logrado una substancialidad excesivamente consistente.

Lo mismo podemos aplicar a la figura fantasmagórica del joven. Este personaje, vestido de verde oliva que recuerda al joven Jorge Manuel, se asimila a la vez con los olivares del fondo y con la atmósfera movida y está a punto de desaparecer. El hombre carece por completo del sentido substancial y parece un espejismo. El claroscuro bastante contrastado no le favorece para su conformación individual, facilita su disolución e integración en el paisaje en la tierra, y, como conjunto, la imagen parece la prolongación de los olivares del fondo. Pero si esta figura hubiese sido pintada con un sentido más tangible, habría quedado totalmente aislada del resto de la pintura. Al mismo tiempo, la representación del paisaje urbano, que es el motivo principal de la composición, se habría alejado para convertirse en un mero fondo, $y$, así, tanto en su forma como en su contenido el equilibrio de la pintura se hubiera gravemente trastornado.

Podemos decir lo mismo acerca del desnudo sentado a la izquierda con los tradicionales atributos de un dios fluvial: un cántaro del que mana agua y una cornucopia de la que se desbordan frutas y cereales. Este personaje, al contrario que el de la derecha, está configurado con un fuerte sentido plástico, con un claroscuro casi tenebrista. El sol postmeridiano parece concentrar su luz en esta parte, y el hombre en cuclillas, para evitarla, oculta su rostro. Aunque esté dotada de un brillo dorado, la tonalidad ocre monocroma con la que el pintor arregló tanto la figura como sus atributos, se identifica básicamente con la de la tierra, de manera que este desnudo no se diferencia en este sentido de su compañero vestido. La imagen nos recuerda aquel pasaje del comienzo del breve tratado de L. B. Alberti, Della Statua. Da la impresión de que es una configuración provisional, momentánea, que asumió "un terrón de tierra" al pie del espectador situado en la colina que domina este panorama. Ambos personajes son productos de la fantasía y están tratados como tales. En este sentido no se distinguen del grupo celestial. Cada uno de ellos es una imagen casual aparecida en el cielo, en las matas y en la tierra. En contraste con el personaje de la derecha, que abre cómodamente sus manos armonizándose con la tierra castellana que se expande, este personaje con rostro invisible y con piernas recogidas de manera incómoda está pintado con un fuerte escorzo, como una masa compacta. De no haber sido pintado así, no se hubiera armonizado con la representación de la ciudad colindante, hecha con minuciosidad, a pedacitos cúbicos.

El Greco forja su obra de tal manera que cualquier detalle suyo está cautelosamente elaborado según cálculos exactos para que se armonice perfectamente con el conjunto. No solamente la forma, el tamaño, el claroscuro y el color de cada imagen, sino hasta los mínimos detalles como el vigor o la delicadeza de cada pincelada y el espesor o la delgadez de pigmentos delatan su cuidado más cauteloso a la vez que su espíritu extraordinariamente sutil. Y esta maravillosa relación de armonía y equilibrio entre los detalles y entre cada detalle y el todo adquiere su pleno sentido sólo cuando atendemos a la obra no como inacabada, sino perfectamente acabada. Una vez considerada in- 
acabada, esta delicada relación de equilibrio artístico pierde su fundamento y pronto se destruye. El contraste observable entre la imagen borrosa del joven y el plano de la ciudad dibujado de forma precisa y detallada, que él despliega y sostiene con el fin de enseñárnoslo, debe haber sido establecido por el pintor con una clara intención. Este contraste, este 'desequilibrio', es un factor esencial para la armonía del conjunto y es lo que define la intención artística: centrar el foco de atención en el plano. E1 plano, no obstante su descripción cuidadosa, está elaborado con un color neutro, lo menos llamativo posible, o sea, la delgada capa del blanco que deja traslucir el ocre inferior, evitando rivalizar en la jerarquía óptica con la representación real de la ciudad que se desarrolla en el fondo, aunque lo haga a nivel del contenido.

Vista y Plano de Toledo es a un tiempo un retrato de Toledo y un homenaje dedicado a esta ciudad, donde el pintor pasó la mitad posterior de su fecunda vida creativa, que le fascinó desde el primer momento de su llegada, siendo además fuente de inspiración constante.

La corta prosa inscrita por El Greco en el plano ha llamado la atención de todos los estudiosos, puesto que es el único comentario hecho por él mismo sobre su propia pintura. La inscripción, que es una suerte de apología por parte del autor, dice:

"Ha sido forzoso poner el Hospital de don Joan Tavera en forma de modelo porque no sólo venía a cubrir la puerta de Visagra mas subía el cimborrios o cúpula de manera que sobrepujan a la ciudad y así una vez puesto como modelo y movido de su lugar me pareció mostrar la haz antes que otra parte y en lo demás de como viene con la ciudad se vera en la plante.

También en la historia de Nra. Señora que trae la casulla a San Ildefonso para su ornato y haer las figuras grandes me ha valido en cierta manera de ver cuerpos celestiales como vemos en las luces que vistas de lexos por pequeñas que sean nos parecen grandes."

Este último párrafo fue interpretado a la luz del neoplatonismo (D. Davies). Sin negar e1 indudable interés de esta interpretación creemos que el pintor, un asiduo investigador de los fenómenos visuales, debió saber perfectamente que en las luces vistas de lejos ya no se distingue el cuerpo luminoso de su entorno iluminado fundiéndose y convirtiéndose ambos en otro cuerpo luminoso de mayor tamaño, aunque, como es lógico, con menor intensidad lumínica. Nos resulta evidente la razón por la que el pintor tuvo que hacer esta explicación ante su cliente o un contemplador de la obra. Como Cossío ya señaló hace tiempo, el pintor tuvo en cuenta que para cualquier espectador es obvia la proporción desequilibrada entre el tamaño del grupo celestial y la magnitud del paisaje urbano. Lo es sobre todo por la lejanía del grupo que está ubicado mucho más allá que la torre de la catedral, vista a contraluz, sin duda a causa de su resplandor. Sin embargo, a El Greco no se le hubiera ocurrido jamás la idea de reducir este grupo, uno de los motivos más importantes del cuadro, en un grupo compuesto de figuras diminutas con la misma escala que se encuentran en Vista de Toledo del Metropolitan Museum. La escala del grupo de la Virgen y su séquito se deriva exactamente del cálculo que establece su giudizio dell'occhio, el ojo infalible del pintor, el ojo que lleva dentro el compás, y es ni más ni menos la que quiere conservar; no es posible modificarla. Este motivo, que glorifica al santo patrono de la ciudad y, por tanto, loa y admira el honor y la fama de esta, no debe ser tratado en una escala demasiado pequeña, lo cual significaría hacerle una pobre ofrenda.

Además, aunque la leyenda de la Virgen que desciende del cielo con su casulla para imponerla a San Ildefonso no es más que una leyenda-el espléndido retrato del santo (Illescas, Hospital de la Caridad) delata esta lúcida consciencia de El Greco-, ella adquiere tal sentido sólo cuando su historia sea aceptada como una realidad, aunque acaecida en un pasado inmemorial. Si el grupo suspendido en el aire se convirtiese en un simple motivo simbólico o decorativo, dejaría de cumplir su requerida función artística. La apología del cretense, hecha entre bromas y veras, es su astuta trampa puesta en este cuadro para que esta visión tenga su realidad y vida como una visión ante un supuesto contemplador. El pintor está recomendando por insinuación al espectador a que redujera a esta compañía celeste de gran tamaño en un punto luminoso aparecido en lo alto de la flecha de la catedral. Justo como el joven a la derecha y el plano sostenido por él sirven de repoussoir al paisaje del fondo, esta inscripción del plano tiene la misma función respecto al grupo suspendido en el aire. El pintor la dotó del mismo papel de empujarlo a lo lejos. Entre la función otorgada a esta inscripción y la que tiene la lista de los nombres de los monumentos inscrita en el otro lado del plano, su relación se invierte: pues, el observador que quiere identificar cada monumento perdido en el panorama urbanístico del fondo con su nombre, se empeñará en aproximarse al objeto al máximo. Mientras la ciudad empieza a acercarse vivamente a medida que el mismo joven se disuelve y se asimila a la huerta del fondo, el esfuerzo del espectador que intenta alejar al grupo y reducirlo a un diminuto cuerpo 
luminoso quedará anulado por la fuerza inmanente en la misma imagen, que se restablece con su renovada potencia y viveza.

Muchos estudiosos de El Greco que mostraron gran interés en esta mitad posterior de la inscripción grequiana, no sintieron, al parecer, ningún interés en su mitad anterior. Sin embargo, en esta expresión, a primera vista normal y corriente, diríase, casi banal en comparación con otro párrafo, más sofisticado y conceptual, parece asomar, de forma inopinada, uno de los aspectos esenciales de las ideas artísticas de El Greco. Como se muestra muy bien en la manera con que la trató el pintor en su Laocoonte (Washington), la puerta de Visagra constituye uno de los monumentos más representativos y simbólicos de Toledo. El Greco que intentó hacer un fiel retrato de 1a ciudad, lógicamente procuró salvar este motivo emblemático. So pretexto de la maqueta, el pintor quiso también colocar el Hospital Tavera en el centro de la composición en forma más monumental y resaltado que los demás edificios, con fachada a la vista, in maestà. Es decir, lo que El Greco se impuso a sí mismo en esta obra fue: 1) no dañar la apariencia general de la ciudad con sus principales monumentos a la vista; y 2) enfocar una atención especial al edificio que está bajo la dirección de su amigo-cliente. Además, desde el punto de vista formal, la gran masa de las nubes que sostiene el hospital es obviamente requerida para restablecer el equilibrio en el claroscuro del conjunto, cuya distribución sabia nos maravilla. Su pensamiento artístico expresado aquí se resume de esta manera: pintar el motivo principal en el centro de la composición mostrando su aspecto frontal, in maestà. Este pensamiento, que se manifiesta por primera vez en esta obra en forma escrita, es uno de los principios que dominan consistentemente su pintura desde el comienzo: la Trinidad, el Expolio, San Sebastián (Palencia), San Mauricio, el Entierro, etc. La mano de un sayón colocada en el cuello de Jesús del Expolio, bajo esta apariencia ofensiva, no muestra otra cosa que un gesto reverencial por no ocultar la sagrada figura de Cristo de la vista del espectador.

Entre las dos figuras alegóricas de Vista y Plano de Toledo, en comparación con el joven de la derecha, con su rostro visto de frente, de mayor tamaño, su pareja a la izquierda, deshumanizado y de reducido tamaño con rostro de perfil perdido, sumergido en la sombra, parece que, a primera vista, no representa ninguna competencia respecto a su rival. Pero la cosa no es tan sencilla. La figura que no nos quiere enseñar su rostro simboliza, como se conoce, el río Tajo, lo cual implica más cosas. Primero, ella no está situada al borde del río como es habitual, sino en un lugar apartado y elevado respecto a su nivel. Y el agua que mana de su cántaro queda inmediatamente absorbida por la tierra, con la que también se identifica su desnudez. Su rostro oculto simboliza el agua subterránea, la fuente de la riqueza invisible e inagotable, encerrada en la madre-tierra. En comparación con esta, su colega de la derecha representa el aspecto más superficial de la misma tierra sin sentido peyorativo. Gracias a él la vida estructurada de la población prospera como indica el plano sostenido por esta figura juvenil; es eternamente joven, porque eternamente se renueva junto con el ritmo de las estaciones. Sin embargo, el que sustenta realmente todo este ciclo vital, toda la belleza y el valor que florecen en la superficie terrestre, es el desnudo con su rostro invisible como es indicado por su básica identificación cromática tanto con el color de la tierra como con el de la imprimación del lienzo.

Uno de los cuadros más importantes que estaban en la mente del pintor al gestar Vista y Plano de Toledo fue el Entierro del conde de Orgaz. Justo como Vista y Plano trata una leyenda local muy conocida, el famoso lienzo de la Iglesia de Santo Tomé es la obra con la que el pintor griego logró expresar pictóricamente otra leyenda local, menos conocida, tan perfectamente que fue calificada como "la más sustancial y penetrante página de la pintura española"(Cossío).

Las composiciones de ambos cuadros son estrictamente similares. Por un lado, en el Entierro se reúnen numerosos aristócratas, monjes y sacerdotes toledanos colocándose en hilera ocupando toda la mitad inferior del cuadro pintados en retrato en grupo con un realismo extraordinario, jamás visto hasta entonces; y en medio de esta congregación ilustre aparecen los fantasmas de dos santos muertos, San Esteban y San Agustín, para enterrar por sus propias manos al señor de Orgaz, don Gonzalo Ruiz de Toledo, modelo y esencia de la caballería toledana, manteniéndole en sus brazos y, así, mostrándonoslo. Y por encima de esta escena terrestre, pinta una visión de la Gloria presidida por Cristo, que bendice y acoge el alma del caballero. Por otro, la composición de Vista y Plano es el despliegue de un gran paisaje o 'retrato' de la ciudad de Toledo y su entorno que Ilena todo el espacio pictórico, pintado con un realismo extraordinario, asimismo sin precedentes. Y delante de este panorama paisajístico aparecen dos figuras humanas como espejismo: el desnudo a la izquierda, que es una alegoría del río Tajo, el tesoro que sustenta a todos los seres 
vivos de esta región y, por tanto, simboliza su esencia; y el joven a la derecha, que sostiene y nos muestra el plano de la ciudad de Toledo, o sea, su esencia urbanística conceptualizada. Y en el cielo pinta una visión de la Virgen con la casulla rodeada por ángeles, que bendicen y glorifican al santo patrono de esta ciudad.

Esta correspondencia rigurosa observable entre las dos obras no se puede considerar casual, sino causal. El cretense pintó, pues, al final de su vida esta pintura de paisaje, recordando la obra de Santo Tomé de forma clara y estableciendo un paralelismo estrecho entre ambas.

Lo que pretendemos con los análisis morfológicos realizados en las páginas siguientes es, además de la comprensión de la obra misma, el conocimiento de la naturaleza de su fantasía, que la produjo. Por este motivo perseguimos, dentro del limitado espacio, la trayectoria y el modo de comportarse de su fantasía, de su pensamiento efectuado a base de formas e imágenes. $Y$ en este contexto damos una importancia primordial al hecho que nos informa Francisco Pacheco: el pintor griego conservaba en una cuadra "Ios originales de todo cuanto había pintado en su vida, pintado a olio, en lienzos más pequeños."

Al margen del significado de "los originales", está claro que El Greco trabajaba teniendo su producción entera -y seguramente las obra de otros artistas asociadas con ella - como un conjunto orgánico consistente, es decir, como un sistema imaginativo coherente. El pintor tenía, pues, siempre a su disposición el inestimable conjunto del tesoro concretamente materializado para despertar y reanimar el "secreto tesoro guardado en el corazón"(Durero).

Dirijamos la atención al grupo que flota en el cielo. ¿De qué manera podríamos situarlo en el sistema imaginativo de El Greco? Lo que nos evoca primero la composición de este grupo es aquella talla policromada del mismo tema que se conserva en la sacristía de la catedral toledana (fig. j). Al comparar ambas imágenes, se advierte el parecido en su composición principal. Si elimináramos del grupo pintado la bella silueta del ángel acróbata con sus alas desplegadas y a los tres querubines sin alas que, llevando cada uno palmas y coronas de laurel, se precipitan hacia la torre de la catedral, el resto del grupo centrado en torno a la Virgen formaría una masa compacta, aproximándose en gran medida - pero nunca hasta el punto de identificarse- al citado grupo esculpido. San Ildefonso que se arrodilla juntando las manos para recibir de la Virgen la casulla, del grupo escultórico, se corresponde muy bien con el ángel igualmente arrodillado a la izquierda del grupo pictórico, mientras que las dos cabezas que asoman sobre cada una de estas figuras arrodilladas mantienen igualmente una analogía mutua. El ángel de pie que cierra el lado derecho de cada grupo - con una mitra el del grupo esculpido, con las manos juntas el del grupo pintado- también se asimila uno con el otro por su verticalidad ligeramente inclinada hacia la Virgen, a pesar de que uno nos enseña su frente, mientras el otro su espalda. Y entre este ángel de pie y la Virgen asoma una cabeza angélica igualmente en cada caso. En el grupo pintado se encuentra, debajo del ángel de pie, otro ángel arrodillado, de perfil, que no tiene su contrapartida en el grupo escultórico. La silueta de este ángel, que extiende cordialmente su mano izquierda, no obstante, conserva un cierto parentesco con la propia Virgen esculpida.

Lo que nos explica el origen de este ángel de perfil, vestido de color amarillo-limón claro, presente en el grupo celestial de Vista y Plano (fig. b), pero ausente en la talla policromada, es el Bautismo del Hospital Tavera (fig. h). Dicho ángel, que llena el hueco creado entre la Virgen y el ángel de la extrema derecha, es una imagen identificable con la del ángel vestido de rojo que aparece en esta obra igualmente tardía y que llena el hueco entre Cristo y el Bautista. Es probable que se haya utilizado el mismo dibujo para ambas imágenes. El brazo izquierdo que dibuja una curva ampliamente abierta, el rostro en perfil que se dirige ligeramente hacia arriba, el pie izquierdo levantado sobre la punta de dedos, la forma oval irregular creada por la falda de la larga túnica que se expande hacia delante, el peculiar ductus, pinceladas descriptivas de los pliegues rizados en pequeños ritmos, la distribución del claroscuro, etc., en muchos aspectos las dos imágenes coinciden excepto en un punto importante: el ángel del Bautismo carece de alas, mientras que al otro no le faltan.

Si observamos atentamente descubrimos que existe una sutil relación causal en este mismo cambio. Una parte del manto de Cristo portado por el ángel del Bautismo, la parte que cuelga delante de él, se transforma en una parte del manto, igualmente azul -la parte sombreada - que lleva la Virgen del otro cuadro. La mancha azul que se encuentra delante de cada ángel forma igualmente un rectángulo irregular. El resto del manto, colgado detrás del ángel vestido de rojo, tiene también su contrapartida: el ala con el sombreado azul que asoma en la espalda del ángel vestido de amarillo. Esta estrecha relación entre ambas obras indica varias cosas que consideramos de 
importancia. Primero, Vista y Plano no puede haber sido creado antes que el Bautismo del Hospital Tavera. Pues, tanto la postura como el gesto del ángel de esta última obra se explican por sus funciones instrumentales: el pie levantado sobre su punta de dedos es para apoyarse sobre la superficie de la roca de nivel más bajo, mientras que la mano adelantada recoge con delicadeza la punta colgante del manto. Esta actitud reverencial y coherente con su situación del ángel en la tierra, al perderse cualquier sentido práctico, se hace completamente simbólica en el ángel en el cielo: la mano adelantada de este ángel piadosamente sostiene a la Virgen, ya sin ninguna función instrumental, al mismo tiempo que señala la casulla - una función oblicuamente demostrativa. Este sofisticado empleo de un motivo no puede preceder a otro más sencillo del mismo motivo. Segundo, igual que sucede en la mancha del muro vista de Leonardo, aquí las dos manchas azules colocadas entre ambos lados del ángel vestido de rojo fueron vistas por el ojo del pintor con una libertad absoluta, pero con una cierta lógica imaginativa. Tercero, la asociación establecida entre los dos ángeles es 'integrista', no 'aislacionista'; cada imagen es tomada con su contexto general en el que está encajada. La escena celestial compuesta con la Virgen y su séquito es vista por El Greco como equivalente de otra escena terrestre del Bautismo.

Esta relación causal entre el mencionado grupo del Bautismo y el otro de Vista y Plano no es unilateral, sino más bien recíproca, reversible. El Greco no se inspiró casualmente, para pintar el grupo visionario, en el esquema del Bautismo, sino por estar este ya profundamente influido por el esquema iconográfico que definió la composición de la talla catedralicia (fig. j), antecedente iconográfico de la escena celestial. Para comprender lo que acabamos de decir basta sólo comparar la correspondencia existente entre la relación Cristo- el Bautista, del lienzo, y la relación San Ildefonso-el ángel a la derecha, de la talla. Con esta correspondencia se aclara, al mismo tiempo, otra establecida entre la Virgen tallada y el ángel vestido de rojo, que ocupan, cada uno, el intervalo creado entre cada una de las parejas citadas anteriormente. Ahora debemos preguntar por qué la composición de la talla pudo influir en la del Bautismo. La respuesta es porque aquélla estaba ya influida por el esquema iconográfico de este tema. Aquí no estamos interesados en decidir la antecedencia genealógica entre huevo y gallina. Pero sí queremos subrayar la trama a la vez compleja y coherente de la fantasía de El Greco. Entre estas dos iconografías muy diversas entre sí existe, sin embargo, un punto común, que es un ropaje destinado al protagonista - Cristo o San Ildefonsocustodiado por un grupo de figuras humanas. En este sentido son dos ideas equivalentes.

De esta manera, se ha demostrado con claridad el lazo íntimo y estrecho que existe entre los dos ángeles mencionados: uno en la tierra, otro en el cielo. Ahora dirijamos la atención al cambio producido en el color de la túnica de cada uno. El color rojo se ha tornado en amarillo verdoso, el color de hierba fresca. El antecedente directo del lienzo del Hospital Tavera es en su forma y contenido, el Bautismo del Prado (fig. d). En esta obra, quien ocupa el lugar correspondiente al ocupado por el ángel vestido de rojo en la obra toledana, o sea, el espacio abierto entre Cristo arrodillado y San Juan, es un ángel igualmente arrodillado, pero vestido de amarillo-verdoso realizado con pinceladas agudas como 'raspadas de hacha'. Además, el mismo ángel deja asomar en su espalda un ala abierta como en el caso del ángel del grupo celestial de Vista y Plano (fig. b). El vínculo entre este grupo y el cuadro del Prado se hace todavía más patente en el ángel orante de la extrema derecha del mismo grupo, que corresponde casi puntualmente, sobre todo en su claroscuro simplificado y fuertemente contrastado con el ángel que cierra el borde derecho de la escena celestial del mismo lienzo madrileño, salvo en un detalle: este ángel, en lugar de juntar las manos, las cruza sobre el pecho como su compañero de enfrente. Este detalle delata que el ángel de Vista y Plano no ha abandonado su nexo con el ángel del mismo lugar del cuadro del Hospital Tavera. Lo mismo podemos decir respecto al ángel arrodillado debajo de él. Sólo en cuanto a su color de túnica y a su ala izquierda que asoma, la figura se remonta hasta su antecedente del cuadro madrileño, pero en cuanto a su postura y gesto, es una exacta réplica del ángel con túnica roja de la obra toledana del mismo asunto. Respecto a los putti que vuelan debajo de la Virgen, parecen derivarse del Bautismo del Prado. Al menos podemos identificar dos de ellos.

El siguiente análisis nos revelará que la fantasía grequiana opera según una lógica rigurosa, casi matemática.

El ángel a la izquierda que baja la vista y sostiene la túnica roja de Jesús en el Bautismo del Prado abandona su propia cabeza y, en su lugar, absorbe la que asoma a su espalda que, por el contrario, alza la vista, para transformarse en el ángel con la túnica verde del Bautismo del Hospital Tavera. En este proceso de metamorfosis queda igualmente absorbido el motivo del ángel que se arrodilla delante de Cristo alzando sus manos con una admiración exaltada. La transmutación se ha producido tanto en la mano levantada de la 
misma manera y el color verde de la túnica que caracterizan la nueva imagen angélica, como en los mismos trazos más agudos de pinceladas - pero, sin llegar a obtener el mismo carácter ya señalado de 'raspadas de hacha'- que definen tanto la forma del ala desplegada como el claroscuro flameante y relampagueante de la túnica, que deja traslucirse el volumen corpóreo del sujeto. En el Bautismo del Prado se observan dos modos caligráficos distintos: uno caracterizado en la manera de modelar la imagen del ángel azul de la izquierda, otro ejemplificado en la forma más abstracta y 'cubista' de definir la figura del ángel verde del centro de la composición. En la última versión del Hospital Tavera el pintor introduce otro tipo de caligrafía más nervioso y vermicular, que no es identificable con el estilo de Jorge Manuel y que nos recuerda de manera inconfundible aquel estilo caligráfico del joven candiota que pintó la primera versión de la Expulsión de los Mercaderes (Washington, National Gallery).

El ángel con la túnica azul de la obra madrileña, intercambiando la función de una de sus manos con la del ángel que se arrodilla enfrente, se transformó en el ángel con la túnica verde de la versión toledana: en esta el ángel arrodillado ya no alza su mano como su antecesor, sino recibe la caída de la vestimenta de Jesús como el ángel de pie de la obra precedente. En su manera sofisticada, casi simbólica, de sujetar la tela se conecta también con el gesto de aquel ángel verde, antecesor suyo, cuya mano alzada, además de expresar su sentimiento exaltado parece cumplir la función de sujetar otra punta de la túnica del Señor. El ángel de la túnica azul con su vista dirigida hacia abajo pudo integrar la cabeza colindante que levanta su mirada por brotar esta prácticamente de su propio cuerpo: sólo tapando la propia cabeza del ángel podemos trasplantarla sin dificultad en su cuerpo. Gracias a la integración de esta cabeza escorzada y apuntada hacia arriba, el ángel pudo fundirse con el colega arrodillado de enfrente.

Hemos comprendido el porqué del cambio cromático de la túnica entre los dos ángeles de pie correspondientes, que asisten igualmente al Bautismo de Cristo: el antecedente con la túnica azul y su descendiente con la túnica verde. ¿Por qué entonces el ángel arrodillado de la última versión del Bautismo viste ahora de rojo en lugar de verde como su antecesor, que ocupaba el mismo puesto en el cuadro del Prado? Por supuesto, desde el punto de vista de la nueva organización cromática tiene su propia explicación. En esta nueva versión el espacio horizontal alargado que ocupaba antes la mancha roja de la túnica de Jesús ha quedado reducido a menos de la mitad, y la nueva mancha roja extensa que aparece, ahora vertical, compensa esta reducción. Y paralelamente, la mancha azul vertical, partida en dos partes por la cinta roja, de la túnica del ángel que está detrás de Cristo, de la obra precedente, al ser sustituida por una mancha verde en la nueva versión, se traslada a la parte delantera de Jesús transmutándose en otras dos manchas azules - de nuevo interpuestas con una mancha roja- que configuran el manto del Señor. La mancha roja sostenida por la azul en el lienzo anterior se invierte en su relación, siendo ahora la mancha roja quien sostiene la azul. Para pintar este manto, un nuevo motivo, El Greco elimina el ala que asomaba en la espalda del ángel arrodillado. El porqué haber introducido nuevas grandes manchas azules puestas en paralelo, y de haber partido el grupo de los ángeles en dos partes, agigantando al mismo tiempo de manera desorbitada a los dos protagonistas de la escena, Cristo y el Bautista, se explica asimismo por el cambio producido en el formato del lienzo: el espacio pictórico aumentado por un formato más ancho ha tenido que ser llenado por nuevos motivos, como se observa también en la parte superior del lienzo. La mancha azul que corría en dirección vertical, interceptada por una banda roja, ha sido sustituida por dos manchas azules colocadas una al lado de la otra e interceptadas igualmente por una banda roja, pero doblemente ancha. Sin embargo, esta explicación no es suficiente para comprender el porqué de la aparición del ángel con la túnica roja del Bautismo del Hospital Tavera (fig. h).

Lo que permitió al ángel con la túnica azul absorber simultáneamente la cabeza del ángel que asoma a su espalda y la figura del ángel que se arrodilla delante de Jesús debe ser, aparte de las razones ya señaladas, el hecho de que en la fantasía de El Greco estas dos imágenes estaban íntimamente asociadas como algo fundamentalmente idéntico. En realidad, tanto la cabeza del ángel de la extrema izquierda que mira hacia arriba como el ángel arrodillado en la parte central con la misma actitud de la mirada se conectan ambos con el ángel con la túnica roja que recibe con ambas manos la sangre de Cristo en la Crucifixión del Prado (fig. e). La identidad entre el ángel pelirrojo de la extrema izquierda del Bautismo madrileño y el ángel con la túnica roja, igualmente pelirrojo, de la Crucifixión llega a ser hasta en su fisonomía Por otro lado, este ángel es una imagen espejada del ángel arrodillado del primer cuadro excepto su mano adelantada y el color de su túnica; y si nos fijamos en estos detalles el mismo ángel coincide exactamente, como visión tridimensional, con el ángel arrodillado del Bautismo 
toledano excepto su mano levantada. Se comprende que por existir esta extraordinaria concatenación imaginativa detrás de la creación del Bautismo del Hospital Tavera, ha podido acompañarse el cambio a primera vista tan chocante como la aparición del ángel con la túnica roja, igualmente pelirrojo. Y se aclara la razón por qué este ángel sin alas está colocado entre las dos manchas simétricas, que no se apartan demasiado, en su aspecto global, de un par de alas abiertas. Este par de manchas azules corresponden, sin duda, a la pareja de alas desplegadas del mencionado ángel volador con túnica roja de la Crucifixión. Asimismo se advierte que el motivo del brazo del ángel del Bautismo toledano, que se dirige hacia delante en una línea diagonal dibujando una suave curva, se corresponde al motivo del brazo de la Magdalena arrodillada en el lugar exactamente correspondiente en la pintura del Museo del Prado (fig. f). No sólo es eso. El mismo ángel parece estar relacionado con la figura de San Juan que está de pie detrás de esta beIla mujer penitenciaria como indicada en su identidad fisonómica, que no es accidental. En realidad, el motivo de este San Juan (hasta sus rodillas) fue empleado directamente por el pintor para definir la imagen de la Virgen que aparece en el tondo de Illescas con el tema de la Anunciación sólo cambiando los colores de sus vestidos, de verde-rojo a rojo-azul, para adaptarlos a la iconografía tradicional (fig. g). El arcángel Gabriel del mismo tondo ha inmigrado del Bautismo del Prado. La manera de extenderse sobre el suelo de las faldas de su túnica roja, sobre todo, sus facciones angulosas, consumidas, pálidas y nada bellas de esta Virgen, son las mismas cualidades que caracterizan al ángel del Bautismo toledano. Pese a sus gestos diversos, ambas imágenes pueden ser consideradas como gemelas. Ahora bien este pequeño formato redondo tiene recortada una parte del manto y la túnica de la Virgen. El arcángel Gabriel en la parte izquierda, que, como un ser ingrávido, forma una especie de la luna creciente, ha podido aprovecharse sin dificultad de la imagen del ángel que ocupaba el lugar correspondiente de la mitad superior de la composición del Bautismo del Prado, que forma aproximadamente un disco. María, que no puede estar suspendida como el mensajero de enfrente, claramente no ha sido posible adoptar la misma medida. Como se advierte, las imágenes que hemos asociado como sus antecesores con el ángel arrodillado del Bautismo del Hospital Tavera -el ángel arrodillado del Bautismo del Prado, el ángel volador a la izquierda así como la Magdalena penitente de la Crucifixión del mismo museo y, por último, la Virgen de este tondo de Illescas - son comunes en que ninguna de ellas exhibe sus pies. El llamativo pie apoyado en la punta de los dedos que exhibe el ángel del Bautismo toledano no está anticipado por ninguna de estas imágenes que le anteceden. ¿Carece este ángel su prototipo que no faltase este motivo en el sistema compositivo del cretense?

Parece complementar esta falta el Tríptico de Módena: es el ángel que aparece en la parte derecha del Bautismo de Cristo, una de las seis escenas de esta obra primitiva que se conserva en la Galería Estense (fig. c). Este ángel no está de rodillas delante de Cristo, sino está de pie detrás de él. Pero, no debemos pasar por alto los siguientes hechos: 1) el ángel está situado en el lado derecho de Jesús custodiando con reverencia su vestimenta; 2 ) el mismo ángel Ileva una túnica roja y su pie izquierdo visible está levantado en vertical sobre la punta de los dedos; 3) le acompañan dos ángeles y uno de ellos lleva una túnica de color oro; 4) y esta pareja de ángeles acompañantes con fisonomía parecida y con su rostro igualmente vuelto hacia la derecha en tres cuartos, encuentran sus contrapartidas en la última versión de la misma iconografía, aunque repartidas en ambos lados de Jesús. Síntomas de que en su vejez El Greco recuerda con nostalgia esta obra juvenil se manifiesta también en otras obras. Basta constatar solamente la naturaleza extraordinariamente consistente y compleja del proceso imaginativo de El Greco que se transparenta en un fenómeno a primera vista tan insignificante como la aparición del ángel con la túnica roja del Bautismo del Hospital Tavera.

Respecto al carácter consistente de su sistema imaginativo, queremos añadir algo más. E1 Greco, que pintó el Bautismo del Prado estando ya en su cumbre del dominio técnico y maduración estilística, no menospreció esta obra creada en sus días juveniles haciendo depender su esquema compositivo fundamentalmente de ella. El dramatismo se ha acrecentado por el aumento de figuras humanas que crean una cierta sensación de horror vacui, acompañada por el claroscuro violento, y el escenario ha sido trasladado desde un apacible arroyo con vistas abiertas a un rocoso valle con vistas cerradas de alguna serranía castellana. En cuanto a la parte baja de la composición, sin embargo, lo que hizo es esencialmente invertir la posición de los dos protagonistas y sus acompañantes. Es sorprendente observar la fidelidad con la que el torso de Cristo se conserva con la misma inclinación y gesto de juntar las manos. En cuanto a la parte alta, la composición ha sufrido ciertamente un cambio radical. Pero no debemos pasar por alto un detalle im- 
portante: el torrente luminoso que se avalancha, siguiendo el descenso del Espíritu Santo desde e1 cie1o y dejando su estela con forma compleja y extraña de ramificaciones del cuadro madrileño (fig. d). Su antecedente exacto se encuentra en la mencionada tabla del Tríptico de Módena (fig. c) y sólo en ella.

Pero no sólo eso. Como se ve, iel pintor no abandonó el motivo formal de la mancha verdosa que constituía el ropaje de Jesús en la pintura a1 temple! Esta mancha de forma extraña, colindante con el cuerpo de Cristo de la obra prototípica corresponde exactamente, en su forma y color así como en su ubicación, a la túnica del ángel arrodillado, que aparece igualmente junto con el cuerpo desnudo de Cristo y a su derecha, en el cuadro del Prado (fig. d). Su básica identidad se hace patente si eliminamos la cabeza junto con el brazo izquierdo alzado de este ángel.

Después de este análisis imprescindible, retornemos de nuevo al grupo celestial de Vista y Plano (fig. b). Se advertirá que la mancha verdosa que lleva la Virgen y que debe de representar la casulla para San Ildefonso tiene un parentesco innegable con otras dos manchas de la misma tonalidad de verde-amarillo, que representan, cada una, la túnica de Jesús en el Tríptico de Módena y la túnica del ángel arrodillado en el Bautismo del Prado.

Aquí está establecida una clara genealogía entre el ropaje verdoso de Cristo en la escena del Bautismo del Tríptico de Módena, el ángel arrodillado con la túnica verde-amarillo del Bautismo del Prado, y la casulla de color verdoso que lleva la Virgen en Vista y Plano. Se advierte que la estrecha y sorprendente correspondencia entre estos dos últimos y su analogía tanto formal como lumínica y cromática observable entre ambas imágenes es suficientemente grande como para permitirnos suponer una causalidad programática. De hecho, después de observar la imagen del ángel con su mano alzada, si nos fijamos en esta mancha amorfa cuya punta luminosa se proyecta hacia la Virgen ¿no nos causaría la ilusión de que el ángel se evapora de repente, dejando sólo este despojo suyo, que está también a punto de desaparecer? Esta mancha extraña sin forma, como substancia gaseosa, conserva con fidelidad la original distribución del claroscuro, especialmente notable en la parte saliente iluminada, que se conecta con la mano izquierda de la Virgen. Esta parte de la mancha con forma de cono alargado es propiamente hablando, más que una parte de la casulla el desecho del original brazo proyectado del ángel exaltado de la obra madrileña. El proceso del cambio acaecido de la mancha abstracta del Tríptico de Módena a la imagen encantadora del ángel del Bautismo del Prado prosigue su curso y así cierra su circuito, volviéndose de nuevo esta imagen concreta en otra mancha abstracta que aparece en Vista y Plano de Toledo.

Por otra parte, el ángel sentado de espaldas en la extrema izquierda del grupo celestial de Vista y Plano (fig. b) se conecta estrechamente con la figura del pastor anciano que se arrodilla del mismo modo en primer plano de la Adoración de los Pastores (fig. k) pintado para Santo Domingo el Antiguo al comienzo del periodo toledano. La composición de la visión está sin duda asociada también con esta iconografía tradicional. Pero, el mismo ángel por estar suspendido en el cielo y situado al lado derecho de la Virgen dirigiéndose a ella, establece el mayor lazo con el ángel de la Asunción (Chicago) con el mismo gesto de adoración y vestido de violeta claro, muy atractivo con sus reflejos cangianti (fig. i). La identidad es patente en su común silueta, a pesar de que uno muestra su frente y otro su espalda, uno exhibe sus manos, otro las esconde. Es notable la coincidencia de la línea luminosa ligeramente ondulada que corta limpiamente la base de cada imagen. La asombrosa coincidencia entre estas dos imágenes no se limita a estos detalles.

Las dos cabezas que asoman entre este ángel y la Virgen del grupo visionario se corresponden, pues, con los dos ángeles que asoman sobre el ángel con las manos juntas de la Asunción. Es importante la identidad entre el ángel con la túnica verde de este cuadro estadounidense con el ángel que asoma justo sobre el brazo derecho extendido de la Virgen y que se funde con la casulla portada por ella del otro cuadro. El ángel de la visión ya no levanta sus manos como su antecesor, pero la borrosa imagen de una cabeza con largo cuello que sale de su hombro derecho corta la raíz del ala desplegada justo como el brazo alzado del ángel con la túnica verde tapa la juntura del ala que asoma detrás de sí. El más significativo de todos estos vínculos entre las dos imágenes se halla entre la túnica verde que lleva el .ángel de la Asunción (fig. i) y la casulla verdosa portada por la Virgen en Vista y Plano (fig. b) . En este último cuadro entre la mencionada cabeza y la casulla intercepta la mancha rosa horizontal que configura el brazo derecho de la Virgen; en la obra de Chicago la mancha roja horizontal que es el brazo de la Virgen ya no las intercepta, sino, elevándose, las deja cobijarse bajo su protección. Pero, en ambos casos, la mancha verdosa - la túnica o la casulla - se interpone entre la Virgen y el ángel arrodillado a la izquierda. 
No es fácil saber si El Greco aprovechó a sabiendas la mancha verdosa del Tríptico de Módena (fig. c) para la túnica del ángel con sus manos alzadas de la Asunción; tampoco si el pintor ya tenía asociado al ángel con las manos juntas del mismo lienzo en el momento de su plasmación con el Cristo bautizado del mismo tríptico. Pero, es completamente seguro que cuando El Greco pintó el Bautismo del Prado (fig. d) se acordó tanto de la pareja de las imágenes angélicas del cuadro estadounidense como de los dos motivos de la tabla estense (Cristo y su túnica), estableciendo, además, una identificación entre ambos grupos formales. El ángel arrodillado en el centro del cuadro madrileño es una imagen invertida del ángel con la túnica verde de la Asunción (fig. i) cuya mano alzada alcanza el extremo de una cinta roja extendida en línea horizontal justo como ocurre con la mano alzada de aquel ángel. La conexión del cuadro madrileño con Vista y Plano (fig. b) es tan directo como la que establece el lienzo de Chicago con este último.

Como puede verse, entre la Virgen que lleva una casulla en sus manos y el joven que porta un plano de la ciudad (fig. a) se repite el motivo formal básicamente idéntico. Entre ambas imágenes se produce un eco recíproco que atraviesa el ancho cielo de Castilla. Este es uno de los procedimientos que el pintor toledano emplea con cierta frecuencia y que podríamos calificar de musical por estructurar la forma a base de repetir una melodía esencial, un Leitmotiv, o de poético por estar articuladas las imágenes con sus 'rimas.' El citado ejemplo de Vista y Plano no es excepcional, sino sus ejemplos son innumerables. Si citamos sólo algunos se encuentra la misma forma de rimar entre el soldado de espaldas en el primer plano y el violoncelista en el cielo, el ángel volador no invertido y el cadáver invertido en el suelo del San Mauricio, o entre el señor de Orgaz y el ángel portador de su alma, entre el Bautista y el sacristán de espaldas a la derecha y, por último, entre Santo Tomás y el monje agustino a la izquierda, del Entierro del Conde de Orgaz. El constatar este hecho es importante en este momento.

Existe una imagen que establece un parentesco muy estrecho con el joven que nos enseña el plano de la ciudad en Vista y Plano. Es la figura de San Jerónimo que nos muestra una página abierta de la Vulgata en el primer plano a la derecha de la ya citada Adoración de los Pastores (Santander, Fundación Botín) que El Greco pintó para Santo Domingo el Antiguo (fig. k) . La imagen misma de este anciano que vuelve su mirada in contrapposto hacia el espectador, por no estar visto de frente, se aleja en este aspecto del joven del plano. A pesar de esta discrepancia formal, este San Jerónimo se identifica perfectamente con el joven en su función con respecto a cada composición. La razón de llamar al cuadro toledano "vista y plano de Toledo" es porque el joven en primer término a la derecha nos exhibe el plano que corresponde al espectáculo urbanístico real que se desarrolla detrás de él, en el fondo, es decir, porque nos enseña su concepto abstracto, presentado en forma reducida y plana. Mientras que la página de la Biblia iluminada por la vela encendida y sostenida por el anciano es, sin lugar a dudas, el capítulo segundo del Evangelium secundum Lucam, y la razón por la que él nos lo señala es obviamente porque la escena que se está desarrollando a su lado es la actualización de esta descripción hecha por San Lucas. Nos está apuntando el pasaje del evangelio que corresponde a la visión viva y real donde acuden los pastores para adorar al Recién Nacido. Por lo tanto, el cuadro podría titularse con mayor exactitud: Escena y Escritura de la Adoración de los Pastores. En este sentido son dos composiciones equivalentes. De esta manera ambos personajes, que son, cada uno, los intermediarios entre la escena pintada y el espectador, coinciden en que, delante de una escena real, nos muestran su explicación, es decir, su abstracción. Por ser una 'abstracción' tanto lo escrito en la página de la Biblia como lo trazado en el plano, de estos está excluida o derramada su 'substancia' o 'realidad', que es el paisaje urbanístico o la escena alegre de la adoración; pero, cada uno de ellos está representado por su imagen esencial. En el primero esta imagen esencial suya es la figura alegórica del río Tajo (fig. a), y en la última es el Niño Jesús, foco de la atención de todos (fig. k). Y la figura vista en fuerte escorzo de Vista $y$ Plano mantiene una analogía formal evidente con la figura del Niño pintado en otro lienzo. Como indica la estrecha relación que acabamos de descubrir entre la figura alegórica del río Tajo y el Niño Jesús, la primera mantiene la misma relación íntima que el joven de la derecha con el grupo celestial (fig. b) que se dirige hacia la catedral toledana, cuya composición está basada en la iconografía de la Adoración, pero sin el Niño.

La Adoración de los Pastores de la primera época toledana conserva una relación inesperadamente estrecha con Vista y Plano. El hecho de que el dios fluvial del río Tajo, a diferencia del modelo dureriano (el guardián de la izquierda de la Resurrección de la serie kleine Passion) (fig. I) , oculta su rostro con el llamado profil fuyant, en el que gran parte del ojo, nariz y boca desaparece en el otro lado de la línea del contorno, significa que, como hemos anotado, esta imagen simboliza el agua subterránea que beneficia no sólo la 
población urbana de Toledo, sino también los campos cultivados y los bosques de su entorno. Si bien no enseña su rostro y no aparece a la sobrefaz, constituye la base fundamental para el mantenimiento de la vida sobre la tierra, condición necesaria que garantiza al joven a la derecha, o sea, la vida sobre la tierra representada por los olivares del fondo, para que pueda mantener una juventud eternamente renovada.

Sin embargo, el hecho de que el mismo dios fluvial mantenga un vínculo formal estrecho con el Niño Jesús de la Adoración parece indicar un significado más serio y profundo que el pintor quiso implicar con su pintura. Y esto no debe ser ajeno a la elección del tema de la adoración de los pastores para el cuadro que pintó para decorar su propia tumba en Santo Domingo el Antiguo.

"Del Griego aquí lo que encerrarse pudo / yaze, piedad lo esconde, fee lo sella, / blando le oprime, blando mientras huella / çafir, parte que se hurtó del nudo... “
Así pudo cantar fray Hortensio Félix Paravicino a la muerte de su amigo delante de su tumba. Pocos años después, sin embargo, los restos mortales del pintor fueron sacados de la tumba de Santo Domingo el Antiguo y trasladados a la Iglesia de San Torcuato, de la que no tardarán en salir de nuevo. Así, después de ir errante de un lugar a otro, hoy se desconoce por completo su paradero. Una situación triste; nos invita a ser pensativos y una melancolía nos invade. Desde otro punto de vista, empero, la grandiosa vista panorámica de la ciudad de Toledo junto con las colinas de su entorno, pintada en Vista y Plano de Toledo, que constituía su "mejor patria" en su vida, ahora representa finalmente su gloriosa, inmensa e incomparable tumba, en un lugar de 1a cua1 un peregrino despistado, pero bienaventurado se tropieza con y "huella", sin saberlo, su "parte que se hurtó del nudo" hace exactamente 400 años. 